\title{
r \\ O SOFTWARE AUDACITY COMO FERRAMENTA NO ENSINO DE QUÍMICA
}

\author{
Aline Locatelli-PPGECM, UPF, alinelocatelli@upf.br \\ Regina Geller - PPGECM, UPF, $176171 @$ upf.br \\ Marco Antonio Sandini Trentin - PPGECM, UPF, trentin@upf.br \\ Júlio Bernieri - PPGECM, UPF, 159745@upf.br
}

\begin{abstract}
Resumo: O objetivo principal desse artigo é mostrar como uma tecnologia digital, como o podcast aliado ao programa de edição de áudio Audacity, pode ser um instrumento de auxílio a favor do processo de ensino-aprendizagem de Química. Este trabalho foi realizado com alunos do $1^{\circ}$ ano do ensino médio de uma Escola Estadual da região Central do Estado do Rio Grande do Sul, com 20 alunos. Os alunos produziram paródias letras (paródias ou poemas) referente aos conceitos: ebulição, evaporação, condensação e sublimação. As paródias e poemas foram gravadas utilizando o software Audacity e posteriormente foram produzidos vídeos com destaques nas letras no programa Movie Maker os quais foram depositados no YouTube. Observou-se que a inserção desta tecnologia nas práticas pedagógicas no ensino de Química, promove a integração e colaboração entre os alunos contribuindo para o processo de ensino-aprendizagem dos conceitos químicos em questão.
\end{abstract}

Palavras-chave: Podcast, vídeos, youtube, ensino-aprendizagem.

\section{THE AUDACITY SOFTWARE AS A TOOL IN CHEMISTRY EDUCATION}

Abstract: The main objective of this article is to show how a digital technology, such as the podcast allied to the Audacity audio editing program, can be an aid to the teachinglearning process of Chemistry. This work was carried out with students of the 1st year of high school of a State School of the Central region of the State of Rio Grande do Sul, with 20 students. The students produced letters (parodies or poems) referring to the concepts: boiling, evaporation, condensation and sublimation. The parodies and poems were recorded using the software Audacity and later were produced videos with highlights in the letters in the program Movie Maker which were deposited in youtube. It was observed that the insertion of this technology in the pedagogical practices in the teaching of Chemistry, besides promoting the integration and collaboration between the students contributing to the teaching-learning process of the chemical concepts in question.

Keywords: Podcast, videos, youtube, teaching-learning.

\section{INTRODUÇÃO}

Atualmente, a educação enfrenta várias dificuldades, tanto no que diz respeito a capacitação dos professores quanto no comportamento dos alunos que estão imersos nas tecnologias. Há um distanciamento entre o ensino e o interesse em aprender. O que se observa são muitos estudantes apresentando dificuldades em aplicar os conhecimentos adquiridos na escola, nas mais variadas situações de seu cotidiano.

Com o avanço das Tecnologias da Informação e da Comunicação (TIC), esse distanciamento, no processo de ensino-aprendizagem, ficou ainda mais perceptível. Há uma nova realidade subliminarmente imposta dentro da sala de aula e com isso as exigências relacionadas às tecnologias estão cada vez mais presentes. Tantas são as 


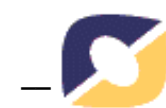

mudanças que é praticamente inevitável não as inserir nos processos educacionais, uma vez que estas estão ligadas ao dia a dia dos estudantes e mesmo dos educadores.

Percebe-se que muitas vezes os alunos não respondem bem a aulas tradicionais, predominantemente expositivas, vindo a apresentar dificuldades na compreensão de alguns conteúdos ministrados em sala de aula. Dessa forma, percebe-se a importância da escolha adequada de uma metodologia de ensino utilizada pelo professor, que muitas vezes não estabelece uma relação próxima com a realidade do educando, ainda mais nos dias atuais.

Esta insatisfação, por não ocorrer a devida compreensão dos conteúdos em geral, revela que há necessidade de mudanças em relação a prática docente. Uma possibilidade para esta mudança é a adoção de novas metodologias, contemporâneas, que empregam tecnologias em suas ações, visando também despertar o interesse dos educandos.

Frisa-se que apenas aulas expositivas "habituais", onde o professor fala e o aluno escuta, ou escreve no quadro e o aluno copia, transferindo as informações do livro para o caderno, não são mais suficientes para despertar no aprendiz a curiosidade e a motivação em aprender. É premente inovar, proporcionar um ambiente interativo e atrativo, que estabeleça relação entre o conteúdo e a realidade dos estudantes.

Atualmente o uso das TIC no ensino traz que o computador, os softwares, lousas e até mesmo os celulares e tablets são bons recursos a serem utilizados e que podem potencializar o processo do ensino-aprendizagem, contribuindo para que a metodologia adotada seja constantemente atualizada pelo educador. De acordo com Kenski (2003, p. 23):

As novas tecnologias de informação e comunicação, caracterizadas como midiáticas, são, portanto, mais do que simples suportes. Elas interferem em nosso modo de pensar, sentir, agir, de nos relacionarmos socialmente e adquirirmos conhecimentos. Criam uma nova cultura e um novo modelo de sociedade.

Para que a aprendizagem realmente seja estimulada e eficaz, acredita-se que seja preciso explorar cada vez mais essas tecnologias em busca de seus verdadeiros potenciais. Dessa forma desvia-se do processo espectador, de somente observar e memorizar, como são desenvolvidas muitas das aulas tradicionais, para um processo mais protagonista e que esse esteja presente em sala de aula como artifício de ensino quotidiano.

Com o aumento expressivo nos últimos anos de ferramentas digitais de autoria gratuitas, sejam na forma de softwares ou na forma online na Internet, acredita-se que a aprendizagem ativa pode ser favorecida, através de atividades práticas na criação e disponibilização de conteúdos digitais. Isso vai de encontro aulas excessivamente expositivas, ainda comuns nos dias de hoje, permitindo assim alternativas de ensino e aprendizagem na escola.

Entretanto, é necessário que os professores atualizem suas práticas tradicionais de ensinar, seja ela qual for, e familiarizarem-se com as novas ferramentas tecnológicas disponíveis na atualidade para que possam inseri-las em determinados momentos na escola. Com isso, espera-se aumentar a atração, atenção e despertar o encanto no aluno em relação aos estudos, aguçando o empenho e o interesse pela aprendizagem, para que se possa alcançar os objetivos educacionais desejados.

A finalidade deste artigo é sensibilizar o educador de como ele pode estar aderindo a uma tecnologia digital, como o podcast, em sala de aula, agregando possibilidades de uso desse meio e suas principais potencialidade e limitações, a favor do processo de ensino-aprendizagem. 


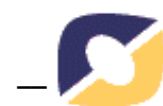

mudanças que é praticamente inevitável não as inserir nos processos educacionais, uma seus aspectos de produção e distribuição de áudio, acrescendo, em razão disso, possibilidades pedagógicas próprias dessa tecnologia. Dessa maneira, podem ser várias as formas de utilização deste recurso pelo educador e a escola.

Assim, este artigo tem como objetivo principal mostrar como o podcasting, aliado ao programa de edição de áudio Audacity, pode ser um instrumento de auxílio na inserção desta tecnologia nas práticas pedagógicas no ensino de Química, além de promover a integração e colaboração entre os alunos.

\section{A TECNOLOGIA PODCAST E O ENSINO DE QUÍMICA}

O podcast é uma mídia de áudio fortemente ligada à Internet, mas que guarda muitas semelhanças com uma brincadeira "clássica" dos anos 1980, quando as crianças usavam gravadores de fita cassete para gravar seus próprios "programas de rádio", ou também pode-se afirmar que o podcast trata-se de "um processo mediático que emerge a partir da publicação de arquivos áudio na Internet" (Primo, 2005, p. 17). A diferença é que agora qualquer pessoa com acesso à Internet pode ouvir esses programas e, ainda por cima, eles podem deixar de ser uma simples "brincadeira" e se tornarem um apoio para a educação. Sendo gravado por uma só pessoa ou por um grupo de amigos, apresentando uma seleção de músicas ou um bate-papo informal, fazendo uma edição bem-acabada ou mantendo o áudio "bruto" por opção, o podcast tem múltiplas facetas.

A miniaturização dos dispositivos de áudio, bem como a incorporação de funções de tocador de MP3 em telefones celulares, associa a gravação sonora e execução do podcast a diversos aparelhos, além de possibilitar sua escuta em várias situações e momentos do dia a dia, facilitando em muito o seu emprego.

Cabe ressaltar que o conceito de podcast envolve também outras características peculiares, tais como a transmissão via Internet, sua distribuição para seguidores inscritos, periodicidade de publicações, dentre outros. Mas, assim como já feito com outras tecnologias digitais na Internet, educadores vislumbraram o potencial do podcast para a educação e se apropriaram dele, explorando alguns de seus recursos mais que outros.

Como em qualquer tecnologia educacional de uso simples, direto e atrativo, o uso do podcast pode levar a uma alta interatividade com o usuário, proporcionando ao educador e educando grande experiência no processo de ensino-aprendizagem, com resultados que visa ajudar ambos a alcançarem os objetivos educacionais propostos, facilitando a produção de atividades com o propósito de intensificar o aprendizado. Contudo é importante inferir que a utilização deste material requer um pouco de conhecimento e domínio sobre esses recursos por parte do professor.

Ao utilizá-los, o educador pode associar informação, entretenimento, dinamismo, rapidez e eficácia ao processo de ensino-aprendizagem, além de motivar e incentivar o educando para a aprendizagem de determinados conteúdos, respeitando os diferentes ritmos de aprendizagem com baixo custo e fácil acessibilidade por ambas as partes.

Leão (2011) afirma que uma das vantagens da produção do podcast é que eles não precisam de elevados custos para elaboração. Afinal, Freire (2010, p. 114) afirma que para a realização de um podcast:

[...] basta ao produtor possuir um computador de capacidade média, fone de ouvido ou caixas de som no seu PC, um microfone (de preço bastante reduzido em modelos mais simples, girando em torno de $\mathrm{R} \$ 10$ ), um programa de gravação e edição de áudio, como o Audacity e uma conexão com a internet de velocidade média. 
Atualmente, uma alternativa para a gravação de um áudio é através do uso de um smartphone. Posteriormente a gravação, este áudio pode ser enviado para o computador, a fim de ser editado no Audacity.

Pensando na utilização de recursos tecnológicos para o ensino de Química, o Audacity se mostra bastante útil. Idealizado por dois estudantes da universidade norteamericana Carnegie Mellon University em 1999 e posteriormente lançado no ano de 2000 como software de código aberto pela SourceForge, o Audacity pode ser utilizado para qualquer finalidade pessoal, comercial, institucional e educacional e por se tratar de um software livre, pode ser instalado em quantos computadores forem necessários. Em setembro de 2018 (data da escrita deste artigo) superou os sessenta milhões de downloads através da plataforma FoosHub ${ }^{1}$.

O Audacity é um software utilizado para gravação e edição de áudios. Além de ser gratuito e possuir versões para diferentes sistemas operacionais (Windows, Linux e MacOS), está disponível em mais de cinquenta idiomas e conta com diversos recursos sonoros que justificam a grande utilização dentro da finalidade educacional. Por contar com a vasta gama de recursos aplicáveis de um software gratuito, começou a se utilizar desse para a construção de ferramentas educativas a fim de ser utilizado como mais um recurso para auxiliar no processo de aprendizagem em salas de aula.

Entre tantas formas de se utilizar o Audacity, está a gravação e edição dos podcasts. Moreno e Heidelmann (2017, p. 17) afirmam que:

\begin{abstract}
O uso de áudio digital (ou podcasts) como ferramenta didática ainda é modesto no Brasil, mas o potencial é imenso, especialmente em face da possibilidade do discente compreender ou complementar conteúdos fora do contexto da sala de aula, por exemplo, ouvindo no smartphone durante o seu transporte. Essa técnica é conhecida como aula invertida (ou flipped classroom) e, naturalmente, não se aplica apenas aos áudios.
\end{abstract}

Dois repositórios, o Banco Internacional de Objetos Educacionais e o Almanaque Sonoro de Química, também citados por Moreno e Heidelmann (2017, p. 17), "merecem atenção quanto ao uso didático de podcasts de Química." Diversos periódicos publicados na Internet descrevem o uso do software para diversas áreas do conhecimento, em maior número voltados a pedagogia. Mas as áreas das ciências naturais também estão presentes no seu uso. Um exemplo disso é o artigo de Martins, Bigansolli e Cruz (2012, p. 30), onde segundo eles:

\footnotetext{
A aplicação do software gratuito Audacity 1.3.13 Beta foi imprescindível por sua facilidade de aplicação e por não haver necessidade de comprar um gerador de frequência, o que certamente minimizou o custo do experimento. As demonstrações de ondas eletromagnéticas puderam ser visualizadas através do Experimento de Cubas de Ondas Mecânicas, por observação das figuras formadas durante a ocorrência do fenômeno ondulatório.
}

Visando incrementar o modo tradicional de ensino, porém sem deixar que o uso do Audacity seja monótono e sem coerência com outros recursos e ferramentas de ensino, surge uma possibilidade de quebrar a barreira negativa que os estudantes tem perante os conteúdos da área das Ciências da Natureza e facilitar a busca por uma aprendizagem significativa, duradoura e contextualizada, a utilização tecnológica de programas de computador capazes de interagir, indiretamente, com os estudantes e professores podem fazer com que as aulas sejam mais dinâmicas, dialogadas e acima de tudo funcionais.

\footnotetext{
${ }^{1}$ Disponível em: <https://www.fosshub.com/Audacity.html〉.
} 


\section{ENCAMINHAMENTOS METODOLÓGICOS}

Este trabalho foi realizado com alunos do $1^{\circ}$ ano do ensino médio de uma Escola Estadual da região Central do Estado do Rio Grande do Sul, com 20 alunos.

Inicialmente foi feito um levantamento dos conhecimentos prévios dos estudantes por meio de questionamentos sobre o tema proposto e discutido em sala de aula: substâncias e misturas. Esse conteúdo tem início, normalmente, no $9^{\circ}$ ano e, desta maneira, no $1^{\circ}$ ano do ensino médio esperava-se que os estudantes possuam algum conhecimento prévio sobre tal. Os questionamentos levantados foram: Qual é a diferença entre substância pura simples e composta? Qual é a diferença entre substância e mistura? O que é temperatura de fusão e de ebulição? Apresentar e explicar pelo menos um tipo de processo de separação de misturas.

$\mathrm{Na}$ sequência foi introduzido alguns conceitos sobre o conteúdo proposto e foi feita a divisão da turma em grupos de quatro componentes. Os estudantes foram então conduzidos ao laboratório de informática da escola, para conhecerem o programa Audacity $^{2}$. Foi instalado em cada computador o referido programa e fez-se uma explanação de como se emprega o programa na gravação de áudios.

Em um terceiro momento os alunos foram conduzidos ao laboratório de Química da escola para a realização de algumas atividades experimentais. Tais atividades foram realizadas com intuito de auxiliar os estudantes no entendimento dos conceitos de substância e mistura e suas temperaturas de fusão e ebulição por meio da verificação das mudanças de estado físico.

$\mathrm{Na}$ referida atividade experimental os estudantes verificaram as temperaturas de fusão e ebulição da água pura $\left(\mathrm{H}_{2} \mathrm{O}_{(\mathrm{l})}\right)$ e de uma solução aquosa de cloreto de sódio $\left(\mathrm{NaCl}_{(\mathrm{aq})}\right)$ de concentração $10 \%(\mathrm{~m} / \mathrm{v})$ e completaram os dados obtidos no Quadro 1.

Após a atividade, realizou-se a interpretação de gráficos (temperatura $\mathrm{x}$ tempo) relativos as mudanças de estado de agregação: um representando uma substância pura e outro representando uma mistura no intuito de comparar o perfil que caracteriza cada um deles.

Quadro 1 - Dados obtidos nos experimentos.

\begin{tabular}{|l|c|c|}
\hline \multicolumn{1}{|c|}{ Testes } & Temperatura de Fusão $\left({ }^{\mathbf{}}{ }^{\circ} \mathbf{C}\right)$ & Temperatura de Ebulição $\left({ }^{\circ} \mathbf{C}\right)$ \\
\hline $\mathbf{A}-\mathrm{H}_{2} \mathrm{O}_{(\mathrm{l})}$ & 0 & 100 \\
\hline B- $\mathrm{NaCl}_{(\mathrm{aq})}$ & -6 & 101 \\
\hline
\end{tabular}

Fonte: dados de pesquisa, 2018.

Para complementação das aulas foi feito um esquema no quadro para sistematizar os conceitos de substâncias (simples e compostas), elemento químico, representações químicas e introduzir mais alguns aspectos do conteúdo como substâncias alotrópicas. Realizou-se a leitura do texto "Química e tecnologia-formas artificiais do Carbono" (Novais, 2016), que relata alguns exemplos dessas substâncias e respondeu-se os questionamentos trazidos pelo livro didático. Após, transcorreu no laboratório de química a identificação dos processos de separação de misturas.

Em seguida, os alunos deveriam compor uma letra (paródia ou poema) referente aos conceitos trabalhados (ebulição, evaporação, condensação e sublimação). Cada grupo deveria escolher a música e letra que tivesse mais interesse e afinidade.

Com a letra e a música escolhidas e elaboradas pelos alunos, deu-se seguimento à elaboração e gravação dos áudios com o software Audacity no laboratório de informática

${ }^{2} \mathrm{O}$ Audacity pode ser obtido para instalação em: <https://www.audacityteam.org/download/> 


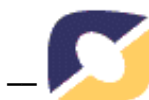

da escola. Os alunos tiveram a oportunidade de sanar suas dúvidas, explorar o aplicativo e posteriormente com o áudio já pronto, foi proposto que fizessem vídeos mais elaborados com imagens e letra das músicas, para uma melhor visualização.

\section{ANÁLISE E DISCUSSÃO DOS RESULTADOS}

O levantamento prévio do conhecimento dos alunos nos possibilita, como professor, desenvolver um olhar mais sensível em relação à formação e entendimento antecipado dos conceitos dos estudantes. Além disso, auxilia na estruturação de uma intervenção didática mais consistente com a realidade apurada. Como Ausubel apud Moreira (2009, p.7) pontua, "se tivesse que reduzir toda a psicologia educacional a um só princípio, diria o seguinte: o fator isolado mais importante que influencia a aprendizagem é aquilo que o aprendiz já sabe".

Nesse sentido, buscou-se levantar as concepções prévias dos alunos sobre o assunto que iria ser abordado ou ao menos que se relacionasse a ele. Para tal, realizou-se questionamentos aos estudantes. No quadro 2 estão indicados os dados obtidos para cada questionamento feito.

Quadro 2: Dados obtidos em relação aos questionamentos de sondagem.

\begin{tabular}{|l|l|}
\hline \multicolumn{1}{|c|}{ Questionamentos } & \multicolumn{1}{c|}{ Análise das respostas apresentadas } \\
\hline $\begin{array}{l}\text { Qual é a diferença entre substância } \\
\text { pura simples e composta? }\end{array}$ & $\begin{array}{l}\text { Nenhum aluno soube diferenciar esses conceitos, entretanto, } \\
\text { devido a palavra "composta" imaginavam que talvez existisse mais } \\
\text { de um composto. }\end{array}$ \\
\hline $\begin{array}{l}\text { Qual é a diferença entre substância } \\
\text { e mistura? }\end{array}$ & $\begin{array}{l}\text { Os estudantes colocaram que em uma mistura deveria ter mais de } \\
\text { um "produto" ou "monte de coisas" juntas. }\end{array}$ \\
\hline $\begin{array}{l}\text { O que é temperatura de fusão e de } \\
\text { ebulição? }\end{array}$ & $\begin{array}{l}\text { Eles lembravam dos diferentes estados de agregação, mas não estas } \\
\text { denominações de passagem/troca de estados físicos. }\end{array}$ \\
\hline $\begin{array}{l}\text { Apresentar e explicar pelo menos } \\
\text { um tipo de processo de separação } \\
\text { de misturas. }\end{array}$ & $\begin{array}{l}\text { Eles não souberam identificar nenhum tipo de processo de } \\
\text { separação de mistura, nem exemplificar de forma correta, mesmo } \\
\text { sem saber o nome exato de um processo. }\end{array}$ \\
\hline
\end{tabular}

Percebeu-se que, apesar dos estudantes terem comentado que haviam visto algo em relação ao que foi questionado, eles não recordavam do assunto. Isso pode ser resultado de uma abordagem menos contextualizada, isenta de significado ou superficial para o estudante. A falta de experimentação também pode ter contribuído para aumentar essa dificuldade de resgate desses conceitos por parte dos estudantes.

$\mathrm{Na}$ atividade experimental, os estudantes, em grupos de cinco integrantes, receberam uma folha para fazerem suas anotações. Neste momento eles apenas deveriam observar o que acontecia em cada processo. Como citado na metodologia, eles deveriam diferenciar uma substância de uma mistura, verificando em que temperatura ocorriam a solidificação e a ebulição em duas situações: I) água pura e II) solução aquosa de cloreto de sódio $10 \%$.

Os alunos relataram que "visualizando o que acontece" parece que a situação faz "realmente sentido", pois para eles saber que a água entra em ebulição e fusão em determinada temperatura já é sabido, porém, eles nunca haviam testado experimentalmente, por meio de medidas de temperatura.

Para a elaboração das paródias, os alunos foram divididos em cinco grupos, de quatro componentes, e norteados quanto a execução da atividade para que a mesma fosse confeccionada com liberdade de escolha da melodia, sem imitações e com abordagem dos conceitos que foram trabalhados. 


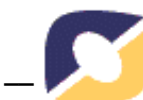

da escola. Os alunos tiveram a oportunidade de sanar suas dúvidas, explorar o aplicativo os áudios. Primeiramente porque em grupo se tornou complicado a escolha de música (melodia) e elaboração de uma letra coerente com o tema proposto em função de que os componentes do mesmo grupo têm pensamentos, ideias e gostos diferentes. Segundo porque como a atividade deveria ser desenvolvida em sala de aula e muitas vezes a internet local não estava funcionando ou estava muito lenta e, em terceiro, que apesar de serem "dominadores" das tecnologias, não conseguiam entender exatamente como funcionava o software Audacity, errando várias vezes no manuseio e até mesmo apagando o que já haviam feito.

Mas mesmo com todos esses "entraves" os alunos se mostraram motivados e entusiasmados e os cinco grupos apresentaram suas letras relativas a quatro paródias musicais e um poema. No quadro 3 apresentam-se descritas as letras confeccionadas pelos cinco grupos.

Quadro 3: Letras elaboradas pelos grupos.

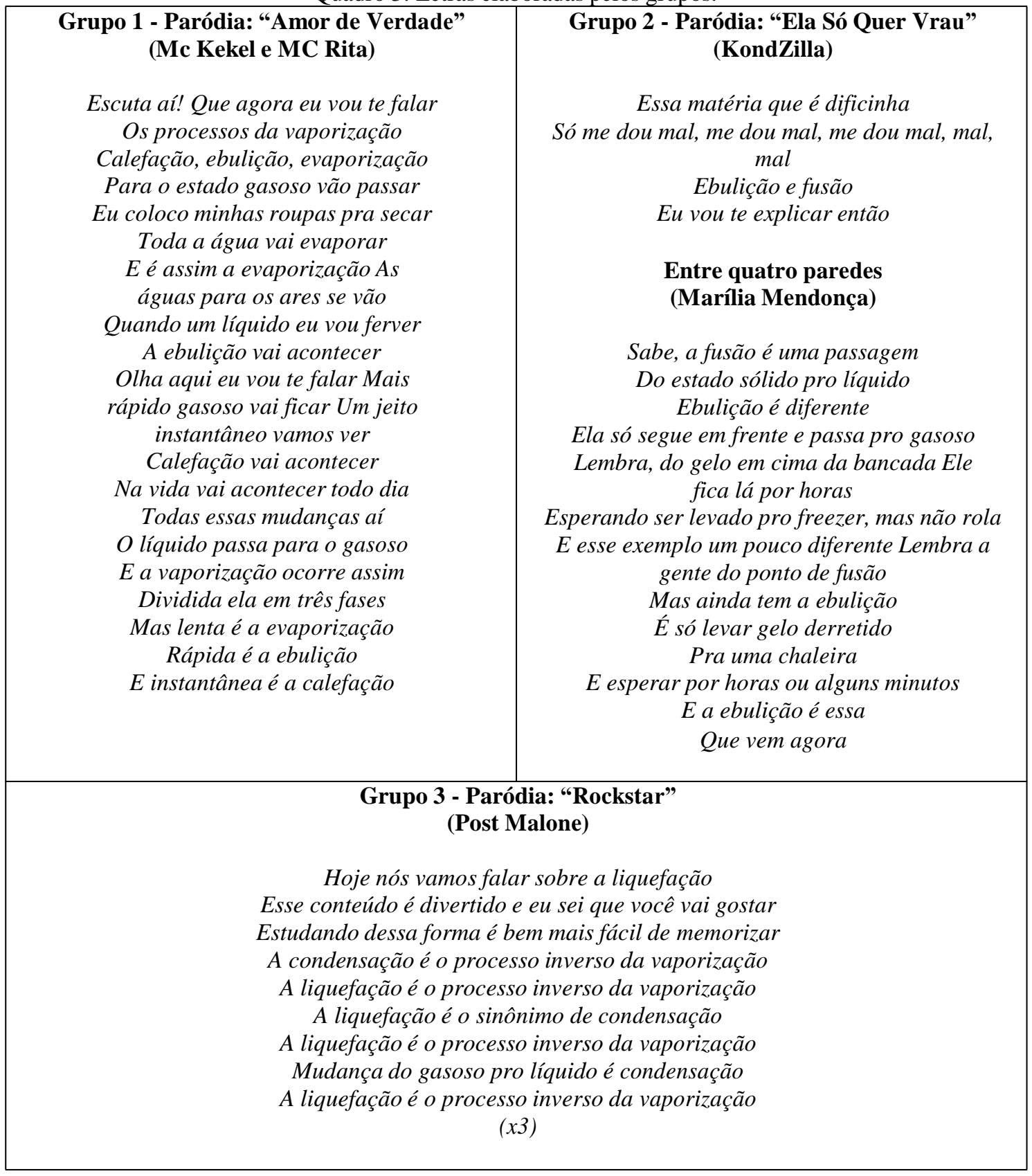


Continuação do Quadro 3:

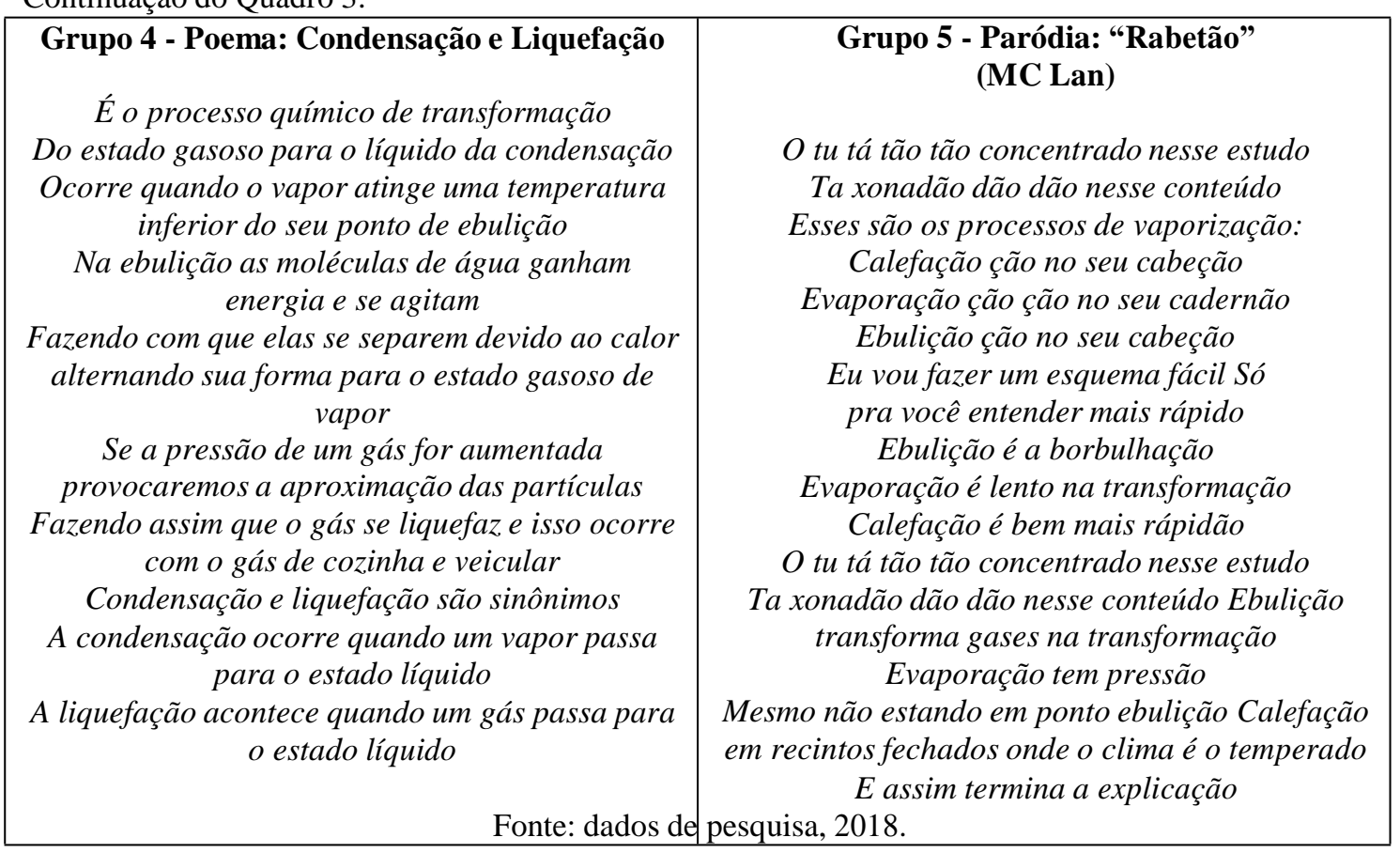

Observou-se que as melodias utilizadas são atuais, conforme Silveira e Kiouranis (2008, p. 30) destacam "[...] são músicas muito atrativas e buscam gerar interesse e motivação, na medida em que utilizam melodias conhecidas e apreciadas pelo público jovem $[\ldots]$ "..

Apesar dos percalços relatados pelos alunos quanto a escolha da melodia, constatou-se que os conflitos nos grupos foram resolvidos e que eles conseguiram apresentar letras bastante interessantes com os conceitos aplicados de forma contextualizada. Corroborando com isso, Silveira e Kiouranis (2008, p. 29) ainda destacam que:

\begin{abstract}
A música e a letra podem ser uma importante alternativa para estreitar o diálogo entre alunos, professores e conhecimento científico, uma vez que abordam temáticas com grande potencial de problematização e está presente de forma significativa na vida do aluno.
\end{abstract}

Salienta-se que a música trata-se de um excelente instrumento de desenvolvimento além de facilitadora do processo de ensino-aprendizagem. Já Bréscia (2003) designa a música como elo de ligação entre o sujeito e seus sentimentos, uma vez que:

[...] a música é como um recurso para o desenvolvimento nas várias fases da vida, desde o início com o pulsar das células se dividindo dentro do corpo da mãe, até no indivíduo adulto, mantendo uma ligação emocional significativa com eventos e pessoas (Bréscia, 2003, p. 25).

Com as músicas e poemas gravados os alunos produziram vídeos destacando as letras das paródias. Tais vídeos foram confeccionados utilizando o software Movie Maker e após a socialização das produções em sala de aula os arquivos foram disponibilizados em um canal no YouTube ${ }^{3}$.

\footnotetext{
${ }^{3}$ Disponível em: <https://www.youtube.com/channel/UC6Pg-u1Wp25ZyHiUsdKIstA>
} 
Nesse sentido, além de fugir dos métodos tradicionais de ensino a música trata-se de uma rica ferramenta, e quando bem trabalhada desenvolve o raciocínio e a criatividade e torna-se uma aliada do professor no processo de ensino-aprendizagem (Ongaro; Silva; Ricci; 2015).

Vale ressaltar que a utilização de podcast pode influenciar espontaneamente na aprendizagem dos conteúdo pelos estudantes, contribuindo para uma aprendizagem mais dinâmica e ativa.

Ficou evidente que a confecção das paródias, aliadas aos podcast, pode ser considerado um recurso que proporciona o desenvolvimento de habilidades $\mathrm{e}$ competências além da criatividade promovendo a assimilação dos conteúdos. Tais paródias aproximaram a linguagem científica da linguagem cotidiana desses alunos, o que pode ser fundamental para a apropriação dos conceitos científicos.

\section{CONSIDERAÇÕES FINAIS:}

Por meio desta pesquisa foi possível observar que o software Audacity aliado aos podcasts podem ser uma estratégia que contribuição para o processo de ensinoaprendizagem dos conceitos químicos em questão.

O podcasting, aliado ao software de edição de áudio Audacity, pode ser uma ferramenta que auxilia a inclusão desta tecnologia na práxis docente no ensino de Química, além de promover a integração e colaboração entre os alunos.

Durante a efetivação dessa atividade evidenciou-se uma maior interação e integração dos alunos no trabalho em equipe. Por mais que eles tivessem apresentado algumas dificuldades na execução da tarefa observou-se que eles conseguiram conclui-la com êxito vencendo as diferenças com o trabalho colaborativo.

Analisando-se as letras confeccionais, observou-se que os alunos conseguiram aplicar os conceitos científicos trabalhos de forma satisfatória. Isso nos faz concluir que a utilização de paródias em sala de aula torna-se uma excelente proposta didática.

Por fim, conclui-se que os podcasts podem ser além de socializadores são um ótimo instrumento de apoio no processo de ensino-aprendizagem e que devem ser cada vez mais utilizados em sala de aula.

\section{REFERÊNCIAS BIBLIOGRÁFICAS}

BRÉSCIA, V. L. P. Educação Musical: bases psicológicas e ação preventiva. São Paulo: Átomo, 2003.

FREIRE, E. P. A. Construindo um modelo de referência à participação ativa dos sujeitos em projetos educativos em ambiente on-line. Trabalho de Conclusão de Curso. (Mestrado em Educação). Universidade Federal do Rio Grande do Norte, Natal, 2010 .

KENSKI, V. M. Tecnologias e ensino presencial e a distância. 3. ed. São Paulo: Papirus, 2003.

LEÃO, M. B. C. (org). Tecnologias na educação: uma abordagem crítica para uma atuação prática. Recife: UFRPE, 2011. 
MARTINS, J. S.; BIGANSOLLI, A. R.; CRUZ, F. A. O. Cuba de Ondas: Uma Atividade Prática para o Ensino de Física Utilizando o Programa Audacity.

Vivências: Revista Eletrônica de Extensão da URI, Erechim: v. 8, n. 15, p. 18-31, out. 2012.

MORENO, E. L.; HEIDELMANN, S. P. Recursos Instrucionais Inovadores para o Ensino de Química. Química Nova na Escola, São Paulo: v. 39, n. 1, p. 12-18, fev. 2017.

ONGARO, C. F.; SILVA, C. de S. RICCI, S. M. A importância da Música na Aprendizagem. Revista Recre@rte, n.3, 2015.

PEREIRA, J. I. M. A. et al. Cinética Química para o Ensino Fundamental: Roteiro de Atividades. São Paulo: PUC, 2010.

PRIMO, A. Para além da emissão sonora: as interações no podcasting. Intexto, Porto Alegre: UFRGS, v. 2, n. 13, p. 1-23, julho/dezembro 2005.

REZENDE, D. D. Podcast. Reinvenção da comunicação sonora. In: Congresso Brasileiro de Ciências da Comunicação, 30., 2007, Santos. Anais. Santos: Intercom Sociedade Brasileira de Estudos Interdisciplinares da Comunicação, 2007.

SILVEIRA, M. P.; KIOURANIS, N. M. M. A música e o ensino de química. Química Nova na Escola, n. 28, p. 28-31, 2008. 